\title{
Violencia sexual y grupos juveniles en el arzobispado de Toledo durante el siglo XVII (los casos de La Estrella de la Jara)
}

\author{
Fernando Martínez Gil *
}

\section{RESUMEN}

Ante los tribunales episcopales de la España moderna pasó una variada gama de causas civiles y criminales que iluminan aspectos inéditos de la cultura popular, los comportamientos

y mentalidades de la época. El Archivo Diocesano de Toledo guarda innumerables procesos, todavia sin catalogar, relativos a conductas de religiosos y seglares que causaban escándalo público pero que no eran competencia de la Inquisición por no atentar contra los principios de la fe. Un caso insólito, al menos en relación

con el resto de las causas, sobre unas violaciones colectivas cometidas en 1625 por los mozos solteros del pueblecito toledano de La Estrella, jurisdicción de Talavera de la Reina, sine al autor para reflexionar sobre el uso de la violencia sexual y las formas juveniles de sociabilidad y diversión en la España rural del Antiguo Régimen.

\section{ABSTRACT}

The episcopal tribunals of $17^{\text {th }}$ century Spain have witnessed a wide range of civil and criminal cases which highlight unpublished aspects of the popular culture, behavioural patterns and mentality typical of the times. Innumerable trials may still be found uncategorized in the Diocesan Archives in Toledo, trials which relate to the conduct of laymen as well as churchmen who caused public outcy but were not placed under the jurisdiction of the Inquisition so as not to commit any outrage against the principles of the faith. The writer highlights one unusual case, at least compared to the rest, which deals with a couple of collective rapes commited in 1625, by unmarried youths in the Toledan village of La Estrella, in the territory of Talavera de la Reina, in order to reflect upon the use of sexual violence and the forms of sociability and amusement employed by young people in rural Spain from the $16^{\text {th }}$ to the $18^{\text {th }}$ centuries.

* Universidad de Castilla-La Mancha. 
El pequeño lugar de La Estrella, cercano a la villa de Talavera, de la que dependía jurisdiccionalmente, celebraba la fiesta de la Candelaria el 2 de febrero de 1625. Las justicias locales, sin embargo, hubieron de atender a las obligaciones de sus cargos cuando una mujer forastera que dijo ser viuda y llamarse Manuela Morena, vecina de Madrid, se presentó llorosa en casa del teniente de alcalde, a la sazón Diego Ramírez de Aguilera, para formular una querella. Aquella noche, encontrándose de paso en La Estrella en compañía del matrimonio formado por su prima, María Cebriana, y el marido de ésta, Francisco Pérez, había buscado refugio en un hospitalito situado en las afueras. Pasada ya la medianoche, cuando estaban acostados, sonaron recios golpes en la puerta; y habiéndose identificado los que llamaban como la justicia del lugar, les franquearon el paso. Entraron cuatro hombres jóvenes embozados, uno de los cuales, moreno y bizco, que se decia el alcalde, pidió a Pérez la carta de matrimonio acusándole de amancebado. Después de examinarla atentamente y habiéndose convencido de su autenticidad, su interés se trasladó a la mujer sola, sobre la que se abalanzó echándole mano al sexo, pero no pudiendo vencer su resistencia optó por sacarla al corral con la ayuda de sus cómplices y allí, sujetándola por pies y manos, unos doce hombres "se aprovecharon de ella hodiéndola y después desto la dieron de bofetones diciéndola entre la puta que ahora iremos por la casada y haremos otro tanto". Pérez se guardó de inmiscuirse porque, según se justificó, le habian amenazado efectivamente con hacer lo mismo con su esposa y con darles muerte. Pero el matrimonio tuvo el valor, al día siguiente, de testificar en apoyo de la querella presentada por Manuela Morena. Mientras los demás les amedrentaban con las espadas desenvainadas, declararon, el supuesto alcalde mató la lumbre con la suya y trató de forzar a la mujer, que gritaba "prima mía de mi alma, ¿cómo no me ayudas?» y «favoréceme, cuñado y parienta, que me riesgan la natura con los dedos". Fracasado el intento, Manuela fue sacada al corral, donde la banda al completo consumó brutalmente la violación. La justicia tardó dos dias en reaccionar $y$, atendiendo a las descripciones proporcionadas por la víctima, fue en busca de los hijos de Alonso Mirado y en especial de un tal Tomás Martín Jarillo, mozo conflictivo que parecía ser el que se habia hecho pasar por alcalde y encabezado la acción. Por supuesto, ninguno de ellos estaba en sus casas, a las que, con toda probabilidad regresarían al día siguiente, cuando les informaron de que, ¿para su sorpresa?, Manuela Morena acababa de otorgar ante el escribano carta de apartamiento renunciando a su querella "por servicio de Dios nuestro Señor y porque se to han pedido personas honradas".

Así comienza uno de los procesos más extensos (unos 400 folios) entre los que, pertenecientes a la primera mitad del siglo XVII, conserva el Archivo 
Diocesano de Toledo en un ingente fondo que todavia no ha podido ser catalogado convenientemente ${ }^{1}$. Los procesos civiles y criminales que se sustanciaban ante el vicario general del arzobispado de Toledo presentan una relativa diversidad: atañen a la conducta moral de los eclesiásticos, pero también se refieren a determinados casos en que se ven involucradas exclusivamente personas seglares, como amancebamientos, separaciones y divorcios, alcahuetería y prostitución, ceremonias y festejos deshonestos, blasfemias y hechicerías no suficientemente constatadas y, en general, todos aquellos comportamientos que causaban escándalo público y eran rayanos con los que entraban claramente dentro de las competencias de la Inquisición ?. Al no llegar a implicar estos delitos un cuestionamiento deliberado de los dogmas de fe, solían ser castigados con sentencias no excesivamente severas al menos en lo que respecta a la represión física y a la privación de libertad, que no en lo que se refiere a la violencia ejercida sobre las conciencias. En este contexto el proceso de La Estrella es a todas luces insólito y el hecho de que hoy se conserve entre los papeles del tribunal vicarial se explica por la apelación llevada a cabo por uno de los acusados, ya que Talavera, cuya justicia ordinaria juzgó el caso en primera instancia, era un señorío eclesiástico que pertenecia al arzobispo.

El lugar de La Estrella forma parte de la comarca de La Jara toledana y está situado al sur de la cuenca del Tajo, junto al último estribo de los Montes de Toledo, a siete leguas de Talavera de la Reina y a veinte de Toledo, sus principales referencias jurisdiccionales. Sesenta años antes de que se desarrollaran los hechos reseñados, contaba con 240 vecinos ${ }^{3}$, que en 1691 se verían reducidos a $180^{4}$. Según los informantes de las Relaciones de Felipe II, La Estrella se hallaba en tierra templada, áspera, ni muy montañosa ni muy rasa. La caza debía ser uno de sus principales recursos y, aunque con escasos pastos comunes, contaba con pequeñas dehesas para el ganado de labor, dos de ellas concejiles y una privada, donde se criaba algún ganado "cabruno, vacuno y ovejuno". Era una tierra de labranza pobre en la que se sembraban "trigo y cebada, y la más parte se coge y siembra cebada por ser tierra miserable de pan". La

Archivo Diocesano de Toledo, Pleitos Civiles y Criminales, año 1627

2 Sobre el funcionamiento de un tribunal eclesiástico, véase la obra de M. ${ }^{a}$ Luisa CANDAU Chacon, Los delitos y las penas en el mundo eclesiástico sevillano del siglo XVIm, Diputación de Sevilla, 1993.

3 ViNas, Carmelo y PAZ, Ramón, (transcriptores), Relaciones histórico-geográfico-estadisticas de los pueblos de España hechas por iniciativa de Felipe II. Reino de Toledo, Madrid, C.S.I.C., 1951, vól. I, pág. 408.

4 JiMÉnEZ DE GREgonio, Fernando, Contorno geográfico-histórico de La Estrella de la Jara, La Estrella, Asociación Cultural Recreativa "El Pilar», 1982, pág. 14. 
mayor parte de sus habitantes eran labradores o "trabajadores" (jornaleros) que vivian pobremente en míseras casas "de cimientos de piedra piçarreña... y otras casas retamizas de retama cubiertas". Como se indicó, ef lugar formaba parte del señorío arzobispal y anualmente el corregidor de Talavera le proveía de justicias nombrando a un alcalde, un escribano, tres regidores, un alguacil y dos mayordomos. Como sucedía en aquella época con el resto de las comunidades rurales de Castilla la Nueva, las devociones particulares de los lugareños denotaban su fragilidad, sus temores y dependencias, pues rendían culto a santos especialistas en la pestilencia (San Sebastián), la piedra o granizo (Santa Ana) y la langosta (Santa Perpetua). Las Relaciones dan noticia finalmente de la existencia de un hospital que gozaba de $400 \mathrm{mrs}$. de renta anual pero precisan que, ya en aquel tiempo, estaba "caído parte de él»" 5 .

En dicho hospital se desarrollaron los hechos violentos de los que fue víctima Manuela Morena en la noche del 1 al 2 de febrero de 1625. Tal como han sido narrados podrían reducirse a una simple, aunque llamativa, anécdota con escaso interés para el historiador que se esfuerza por que lo insólito no desvirtúe su idea de la realidad. Varias razones, sin embargo, me han llevado a prestar especial atención a este proceso. En primer lugar, su larga duración y riqueza de contenido, ya que el episodio de la violación sólo fue el inicio de complejas derivaciones que tuvieron en vilo a todo el pueblo. El carácter de insólito o extraordinario que se aplique a un suceso, además, no le priva de su potencial explicativo de un contexto social; es más, la ruptura de la normalidad permite descubrir disfunciones, conflictos, motivaciones de conductas y fundamentos de relación social que permanecen soterrados, invisibles, bajo el imperio de una aparente y acorazada normalidad, y a los que por supuesto el método cuantitativo no puede acceder. Por si fuera poco, hechos como los que aquí nos ocupan, sin dejar de ser extraordinarios, no me parecen absolutamente insólitos, pues el examen de la documentación aporta un caso semejante y deja traslucir la posible ocurrencia de otros que, por no haber sido denunciados o no haber entrado en juego la diversidad de factores que aquí concurrieron, no han dejado huella en los archivos.

El interés del caso de la violación colectiva de Manuela Morena se refuerza además por el hecho de que, sin intervención de ella, de la que no volvería a saberse después de su renuncia y su inmediato abandono del lugar, fue reactivado dos años más tarde por la justicia talaverana. El 27 de julio de 1627, en efecto, su alcalde mayor, el licenciado Alonso de

5 Viñas, Carmelo y PAZ, Ramón, op. cit, págs. 405-409. 
Castañeda, ordenaba comparecer al escribano de La Estrella ante el que la víctima había formalizado su apartamiento de la querella; y haciendo gala de un rigor que no pudo sino sorprender a los lugareños, envió alguaciles para que prendieran a los presuntos culpables: el cabecilla Tomás Martín Jarillo y dos de los hijos de Alonso Mirado.

¿Qué había despertado el celo del alcalde mayor dos años después de que ocurrieran los hechos? La justicia de Talavera no había tenido en absoluto conocimiento de ellos. Fue un caso de mucha menor importancia el que la puso en guardia. Un vecino de La Estrella, Antonio Bolonio o Polonio había sido víctima de una paliza en la taberna. Su agresor, un "moço moreno que mira a bizco", "alto, gordo y ojos bajos, que parece que está dormido y mira bizco", respondía al nombre de Tomás Martín Jarillo. Naturalmente salió enseguida a relucir el episodio del hospital. El alcalde mayor sintió crecer su indignación al conocer que uno de los mozos se había permitido suplantar impunemente a la justicia con fines delictivos. Pero lo que más le irritó fue la inoperancia de la justicia lugareña y el hecho de que ésta no hubiese dado cuenta del caso a las autoridades de las que emanaban sus competencias. Por si fuera poco, la cuestión ponía al descubierto una autonomía excesiva, y por ello peligrosa, de unas justicias locales que ignoraban a las superiores instancias a las que jurisdiccionalmente estaban sujetas. Intervenir en el caso era para Castañeda hacer valer la autoridad de la villa y escarmentar a quienes habían osado actuar al margen de ella.

Los culpados tuvieron tiempo de abandonar sus casas antes de la llegada de los alguaciles, que solamente pudieron encontrar al escribano Sebastián de Aguilar. Su declaración, muy escueta, aportó sin embargo un dato que arrojaba alguna luz sobre la extraña renuncia de la víctima a su querella: había sido doña María Dorotea, esposa del regidor de Talavera don García de Cardenal, quien solicitara los servicios del testigo porque, según le dijo, Manuela Morena se queria apartar de su derecho.

Pocos días más tarde, el 27 de agosto, se presentó en Talavera el propio Tomás Martín Jarillo, que ingresó en la cárcel después de declararse inocente y dar poder a sus procuradores. El alcalde mayor, por su parte, nombró a Pedro González Tonel fiscal del proceso y éste comenzó su actuación acusando de negligencia al alcalde de La Estrella y calificando el delito de "uno de los más graves y atroces que han sucedido". El dia 2 de septiembre, el interrogatorio de los testigos proporcionó, en fin, valiosos datos a la instrucción del proceso. Según Francisco de Mercado, entonces alcalde del estado de los hijosdalgo, el delito había sido cometido por diez o doce mozos, de los que solamente conocía la identidad de dos: Jarillo, 
hijo de la mesonera, "bizco de un ojo", y «un hombre alto robusto con mella en la parte de arriba", señas que correspondían a la persona de Pedro Gómez. Obligado a declarar el hermano de éste, delató además a Miguel Mirado, a quien otro testigo describiría como un «moço hosco, con un lunar en un carrillo", y a un gallego, muy posiblemente Pascual Moreno, que era criado del matrimonio Cardenal-María Dorotea. Ambos testigos coincidieron en que ésta había sido la mediadora y quien convenciera a la mujer de que se apartase a cambio de una compensación de 30 reales recaudados entre los mozos. A su parecer, nada justificaba el rigor de la justicia pues "se lo habían pagado a la dicha mujer».

Tales razones no convencieron a Castañeda que decretó la prisión de Diego Ramírez de Aguilera, teniente de alcalde el dia de autos, y reiteró la orden de captura de los presuntos culpables y el embargo de sus bienes, a lo que Jarillo respondió pidiendo que se le tomase confesión y amenazando con apelar a la chancillería de Valladolid. La negativa del alcalde mayor se basó en que no debía tomarle confesión mientras no se completase el sumario y en su convencimiento de que el delito era "de los más graves que han sucedido en esta tierra ni en el reino".

El 14 de septiembre el propio alcalde mayor se trasladó al lugar de La Estrella, acompañado del fiscal, un escribano y varios alguaciles. Al día siguiente tomó declaración a una decena de testigos. La mayoría de ellos se mostraron reticentes ante la justicia foránea y protegieron con sus ambigüedades y silencios a quienes se sentían unidos por redes de solidaridad familiar y local. Pero la acumulación de detalles fue suficiente para que el rompecabezas fuese tomando forma. El alguacil Pedro García Retamal identificó a los cuatro jóvenes que habian irrumpido en el hospital: Tomás Jarillo, Pascual Moreno, Miguel Mirado y Pedro Gómez, todos mancebos ${ }^{6}$. El testigo, a instancias de doña María Dorotea y del teniente de alcalde, se encargó de cobrar los 30 reales de los mozos del lugar, algunos de los cuales, sin reconocer su culpa, "por quitarse de ruidos 10 daban». El teniente de alcalde aseguró que habia cumplido su obligación llevando a cabo una información de lo sucedido, pero se hizo innecesaria cuando la víctima renunció a su derecho y se fue. Todos los interrogados se mostraron incómodos y reconocieron que "el lugar estuvo alborotado" mientras duró la querella, se hablaba de ello en corrillos y algunos

"Vocablo utilizado en el documento en sentido de "soltero". Sebastián DE CovarRUBIAS Orozco, en su Tesoro de la Lengua Castellana o Española, Madrid, Melchor Sánchez, 1674, da del mismo la siguiente acepción: «el moço que está en la edad que en Latín llamamos adolescens. Dixose del nombre mancipium, porque aún se está debaxo del poder de su padre", pág. $535 \mathrm{v}$. 
padres "hubieron pesadumbre" con sus hijos. A los buenos oficios de doña María Dorotea se resistieron algunos mozos; otros, o sus padres, se apresuraron a contribuir "por quitarse de ruidos", aunque negasen su participación o minimizasen el incidente declarando que no se habia hecho agravio a la mujer. Por su parte, ésta se había mostrado firme en presentar su querella contra los forzadores, «y a tres de ellos, si los viera asados, comiera dellos por el agravio que la habian hecho" ${ }^{7}$. Sin embargo, la persuasión de doña María Dorotea logró sus efectos, ya que Manuela acabó aceptando que si le daban los 30 reales "se iria por ser soltera y no trataría de seguir la querella" ${ }^{8}$. Al consuelo proporcionado por la compensación económica hubo de añadirse, a no dudarlo, una presión hostil que debió amedrentar a la forastera, a quien la opinión del lugar y su justicia tendían a transformar de víctima en verdadera culpable de los hechos. Doña María Dorotea advirtió a la mujer que no hiciese mal a la gente del lugar y que, a cambio, le darían alguna cosa ${ }^{9}$. Diego Ramirez de Aguilar, el teniente de alcalde, le dijo "que no anduviese perdida y que se fuese y fuese mujer de bien", diligencia que, al parecer, le agradeció el mismo Jarillo. Según otros testigos, efectivamente, Manuela fue expulsada del pueblo por el alcalde y, al decir de Isabel Hernández, con su marcha "se sosegó el negocio".

Estas declaraciones sirvieron además para engrosar la lista de culpados que, más que mozos (algunos sobrepasaban los treinta años), tenían en común su condición de solteros. Los directamente implicados, al parecer, habían sido los siguientes ${ }^{10}$ :

- Tomás Martín Jarillo, 22 años en 1625

- Pedro Gómez

- Juan Fernández, 32 años, labrador

- Miguel Mirado

- Alonso Mirado, 22 años, trabajador

7 Testimonio de Isabel Hernández, esposa de Pedro Corral y madre de Juan Fernández, uno de los encausados. Manuela Morena vivió en su casa durante los escasos días en que duró la querella.

8 Testimonio del alguacil Pedro Garcia Retamal. Nótese el cambio de estado de Manuela Morena, que en un principio habia declarado ser viuda. Isabel Hernández aseguró además que por aquellos dias se encontraba preñada, lo que más tarde sería ratificado por algún otro testigo.

9 Testimonio del sastre Juan Sánchez, que por entonces trabajaba en casa de Cardenal y doña María Dorotea.

10 Las edades están extraídas de las propias declaraciones de los mozos. Desconozco las de algunos debido a que, en el curso del proceso, no llegaron a prestar declaración. 
- Pascual Moreno, 24 años, trabajador

- Juan Izquierdo, 23 años, trabajador

- Alonso Fernández del Mazo, 32 años, labrador

- Juan Pizarral, 25 años, labrador

- Juan Delgado, 28 años, labrador

- Alonso de la Nava, 23 años, trabajador

- Andrés Sánchez, 23 años, labrador y carretero

- Juan Sánchez, 24 años, labrador

- Gabriel Izquierdo (o García), 28 años, trabajador

Los testigos destacan su condición de "mancebos", describen a algunos de ellos como "moços inquietos" y a todos como "gente del campo que suelen andar de noche". Castañeda había logrado identificar a los culpables pero solamente a uno de ellos, si bien el principal acusado estaba en su poder. No sabemos si su ánimo estaba escandalizado por unos hechos que consideraba insólitos, pero indicios dispersos que se deslizaron a lo largo de los interrogatorios le hicieron sospechar que no lo eran tanto. De este modo el sumario dio un giro inesperado para centrarse en otro suceso acontecido en el verano inmediatamente anterior. Para esclarecerlo ordenó traer nuevos testigos de los pueblos cercanos de Aldeanueva de Balbarroya y Sevilleja de la Jara. A medida que se iban conociendo los hechos, en el alcalde mayor de Talavera crecía la estupefacción. Todo había ocurrido en el curso de los dos últimos años sin que la justicia de la villa se hubiese enterado de nada.

El 16 de septiembre Castañeda tenia ya las claves de este segundo caso, en el que Jarillo también estaba implicado: un nuevo intento de violación, esta vez no consumada. Pero no paraba aquí el historial delictivo del díscolo mozo de La Estrella. Un vecino de Navalmoral le acusó de robarle su reja y su arado, y un vinatero de Talavera se sintió víctima de un timo urdido por dos granujas: uno de sus empleados, al que habia despedido por borracho, y una vez más Tomás Jarillo, que había actuado de cómplice haciéndose pasar por su representante, en calidad de lo cual había cobrado de una cliente 170 reales y una sortija de oro. El empleado huyó con intención de pasar a las Indias mientras que Jarillo, acosado, hubo de devolver su parte del botín fingiendo que habia sido engañado por su cómplice. Ahora bien, el delito más grave en relación con el cual volvía a aparecer el nombre de Jarillo era una segunda fuerza que, también colectivamente, se habia intentado hacia ahora un año, en el verano de 1626. 
Por entonces Catalina Sánchez, que ahora vivía en Sevilleja con su segundo esposo, estaba casada con Juan de la Torre, vecino de La Estrella y ya difunto. Una noche, estando su marido ausente, había dado posada en su pajar a dos hermanos forasteros que se dirigían a Madrid, un muchacho de unos veinte años y una mujer de buena presencia que debía contar los veintiséis y que, según algún testigo, parecía extranjera, flamenca quizás. Antes de acostarse Catalina, que estaba sola en casa con una hija de seis años y un criado de catorce, se cercioró de que el corral quedaba bien cerrado con llave. En plena noche la despertaron las voces de su criado, según el cual habian entrado ladrones en el corral con la intención de robar lechones. Pero los gritos que le llegaron a continuación desmintieron esta interpretación apresurada, pues eran de la mujer forastera, cuyo hermano empezó a aporrear la puerta de la casa asegurando que muchos hombres se la llevaban. Catalina, temerosa, no accedió a abrir la puerta y le recomendó que fuese en busca de la justicia, lo que el muchacho hizo. Una hora después regresaron los dos hermanos, ella lloriqueando y herida en una mano de una cuchillada. Les acompañaban, entre otros, el nuevo alcaide Pedro Martín Jarillo y el alguacil Juan Gómez. Entonces pudo enterarse por boca de la víctima que dieciocho o diecinueve hombres (hasta treinta los elevaria luego) habian desquiciado la puerta del corral y la arrastraron hasta las eras con la intención de forzarla, pero la llegada de la justicia a instancias de su hermano les había puesto en fuga. En su condición de forastera no le era posible identificar a sus agresores, pero se murmuraba que en la "travesura" habían participado Tomás Jarillo y un hijo del carnicero Navalón, ambos "moços inquietos". El criado Gabriel Sebastián ratificó lo declarado por su ama y precisó que él había podido ver a seis u ocho hombres embozados. Al día siguiente el alcalde, el escribano y Diego Ramírez de Aguilera ${ }^{11}$ hablaron en secreto con la mujer y ésta y su hermano se apresuraron a abandonar el lugar aquel mismo dia. Un vecino en cuya casa servía ahora este testigo le había advertido de que no culpase a nadie, pero la amenaza no había arredrado al joven criado en su voluntad de colaborar con la justicia. Según declaró, el hijo del alcalde, Pedro Martín de Ribera y mozo de 24 años, le había confiado cuando los dos se hallaban a solas sentados en una cerca que él había participado en los hechos, si bien asustado por el cariz que estaban tomando se había ido a casa sin entrar al corral. Días más tarde escuchó lo mismo de labios de Juan Mirado y de Juan Buenamigo (21 años), quienes delataron a su vez a Alonso de la Nava (24 años) y al propio hijo del alcalde.

\footnotetext{
1 El que habia actuado como teniente de alcalde en el primer caso de violación.
} 
El escribano Sebastián de Aguilar se veía una vez más en el ojo del huracán. Interrogado por Castañeda, contó que el alcalde habia tomado el testimonio de la víctima, de la dueña de la casa y de su criado, pero que renunció a abrir cabeza de proceso al comprobar que la mujer ofendida no había reconocido a nadie, tanto más por ser forastera y extranjera, que no entendía bien lo que le preguntaban. Y ello a pesar de que todo acusaba a Tomás Jarillo y a los que de noche se juntaban con él. El escribano recordaba que, hacía un año, el propio Jarillo le había confesado que una noche dio una paliza a un albañil forastero "porque estaba hablando con una mujer casada deste lugar", incidente del que no estaba seguro si se había instruido proceso.

El violento Jarillo era, pues, el blanco de todas las sospechas y acusaciones, pese a lo cual permanecía impune. El fiscal estaba enfurecido y solicitó que se reiterasen las órdenes de busca y captura de sus cómplices. No pudiendo hallar a los culpables, fueron embargadas sus pobres pertenencias, que se reducian a un puñado de rústicas mesas, camastros, arcas, contadas fanegas de trigo y cebada y algunas vacas, becerros y erales. Únicamente pudo ser habido Juan Delgado, que pasó a la cárcel, y pronto siguió sus pasos la mesonera Catalina Jiménez, madre de Tomás Jarillo, empeñada en que su hijo no tenía bienes que embargar, pues los escasos que había dejado al morir el padre, cargado de deudas, le pertenecían a ella. Tomás y sus cinco hermanos, en efecto, se habían visto obligados a renunciar a sus herencias.

Estos primeros prendimientos exasperaron a los vecinos de La Estrella, que se sentían acosados. Uno de ellos, Diego Lucas, se atrevió a proclamar que "los que no tenían culpa en este negocio lo pagaban y no lo pagaba quien lo había hecho". Ante tal cuestionamiento de su justicia reaccionó el alcalde mayor encarcelándolo bajo la acusación de encubrimiento, pues de sus palabras se desprendía que conocía la identidad de los verdaderos culpables. Los dias 17 y 18 de septiembre se leyeron edictos y pregones llamando a comparecer a doce culpados por el primer caso y tres más por el segundo (Martín de Ribera, Buenamigo y Mirado). Se otorgaba una recompensa de 20 ducados al que ayudase a capturarlos y se multaría a quien osara encubririos con 200 azotes tratándose de gente común o de 200 ducados en caso de ser persona principal.

Entretanto el preso Tomás Martín Jarillo, a quien aún no se habia tomado confesión, apeló ante el Consejo Arzobispal, y éste, habiendo conocido el caso, lo volvió a remitir al alcalde mayor de Talavera instándole a "que recibiéndole luego la confesión a Thomas Xarillo proceda en la causa y haga justicia como hallare por derecho". 
De este modo, el 13 de octubre, se procedió a tomar declaración al principal de los encausados. Jarillo confundió al principio la noche de autos con la de la pesadumbre habida con Antonio Bolonio en la taberna, pero después lo negó todo en relación a la violación. Aquel $1^{\circ}$ de febrero había estado fuera de casa, "en su labor», arando a una legua del lugar de La Estrella; había vuelto tarde a casa y se habia acostado sin salir. Ni estuvo en el hospital, ni se hizo pasar por el alcalde, y sólo se enteró de los hechos al día siguiente. No tenía duda de que los culpables de aquel delito eran los mozos del lugar, pero ignoraba quiénes eran en concreto. Tampoco habia huido de casa: fue a su labor y allí supo por su madre que querían prenderle. Buena prueba de lo que decía era que él no había participado en la colecta de doña María Dorotea. En cuanto al segundo forzamiento, negó asimismo toda relación con su persona. $Y$ siguiendo con su táctica de no admitir cargo alguno, negó también el robo del arado ya que entre labradores era costumbre tomarlo cuando se necesitaba y luego devolverlo, como él hiciera. Responsabilizó del timo al empleado del tabernero, a quien éste le debía dinero, y si había devuelto una cantidad al alguacil sólo había sido para quitarse de pleitos. Negó, en fin, haber dado "de espaldarazos" a Antonio BoIonio en la taberna, ya que lejos de tratarse de una pesadumbre, el incidente había sido una "fiesta de esgrima, cosa de entretenimiento y burla".

Después de Jarillo declararon su madre, que ratificó la insolvencia de su hijo ${ }^{12}$, y el alcalde de La Estrella Pedro Martín Jarillo, labrador de 56 años, padre de uno de los implicados en el segundo caso y pariente en tercer grado de Tomás Jarillo. El alcalde relató que, estando acostados él y su hijo, había llegado un joven forastero gritando que forzaban a su hermana. Se levantaron a toda prisa y corrieron en dirección a las eras, de donde vieron venir a una mujer sola llorando, pero no distinguieron a nadie más. $Y$ aunque hizo las debidas diligencias, nada pudo sacar en claro, pues la mujer no fue capaz de identificar a sus supuestos raptores. En esas condiciones resultaba inútil abrir cabeza de proceso, razón por la que ni siquiera consideró que merecía la pena ponerlo en conocimiento del corregidor y el alcalde mayor. Pedro tuvo buen cuidado en negar que su hijo hubiese participado en los hechos y que la negligencia que se le atribuia pudiera deberse a este motivo y a su parentesco con Tomás Jarillo.

12 El marido de Catalina Jiménez habia muerto pobre y con muchas deudas catorce años atrás, por lo que a ninguno de sus seis hijos le habia correspondido herencia. Ni se había podido realizar la partición de bienes ni ella cobrar su dote. Los escasos bienes que Catalina poseía, en buena parte embargados, eran de su propiedad y no de su hijo Tomás, que vivia con ella. Catalina contaba unos setenta años y dijo poseer ocho millares en unas casas y huertas, dos rocines y una mula, casi todo, como se ha dicho, embargado por deudas. 
Una vez tomadas las confesiones, todos, excepto el principal culpado, fueron liberados bajo fianza. Mientras tanto, el alcalde mayor procedia a pregonar un tercer edicto ordenando la comparecencia o prendimiento de hasta quince prófugos; y el fiscal, por su parte, formalizaba las acusaciones contra catorce mozos por la primera fuerza, cuatro más por la segunda, Diego Lucas por su cuestionamiento de la rectitud de la justicia, Catalina Jiménez por ocultar la hacienda de su hijo, Pedro Martín Jarillo por omisión interesada, y en fin Tomás Jarillo nada menos que por siete cargos. En total, sumaban veinte acusados a los que se unió el ex-teniente de alcalde Diego Ramírez de Aguilera, a quien Castañeda también mandó prender "por haber andado remiso en averiguación del dicho delito y prisión de culpados y por no haber dado noticia de la dicha causa".

Los edictos del alcalde mayor comenzaron a causar sus efectos y algunos de los jóvenes buscados comenzaron a aparecer y entregarse en la cárcel de Talavera. El primero de ellos fue Alonso Fernández del Mazo, a quien se tomó confesión el 10 de noviembre. La noche de autos había estado en casa de un pariente donde se daba una fiesta. Allí bailó con algunas vecinas y constató la presencia de Tomás Jarillo y Juan Fernández, que estaban "viendo bailar". Se trataba de un festejo público; la puerta estaba abierta y la gente entraba y salía. Acabado el baile después de las diez, salió a pasear con varios amigos y, pasando cerca del hospital, oyeron un alboroto y a una mujer quejarse. Alli vio a varios mozos arrimados a las paredes del patio y dentro del edificio a Jarillo, Miguel Mirado y Pedro Gómez. Presintiendo que iban a cometer una "bellaquería", el declarante se fue a acostar en casa de un amigo y al día siguiente se enteró de lo sucedido. Es cierto que había entregado cuatro o cinco reales a la víctima, pero lo hizo presionado por algunos de los verdaderos culpables.

La táctica utilizada por el defensor de Fernández del Mazo, colaborando supuestamente con la justicia para salvarle a costa de acusar a Jarilio y a sus fieles, sirvió también a los intereses de Juan Pizarral, que se presentó voluntariamente en la cárcel poco después. También él vio a Jarillo, Mirado y Gómez con una mujer a la que parecia que hacian fuerza; también él optó por retirarse para no verse culpado, "y hubo mucha lástima a la dicha mujer por quedar entre los dichos mozos".

Sintiendo como una traición la delación de sus compañeros, Jarillo y su curador se enzarzaron en una sucesión de réplicas y contrarréplicas con el fiscal. El mozo negó reiteradamente sus delitos menores y la existencia de verdaderas pruebas que le implicasen en las dos violaciones. Él no estuvo allí ni se hizo pasar por la justicia. ¿Cómo podia haber examinado la carta de matrimonio de los forasteros si no sabía leer? Por ser inocente no quiso 
dar ni un real a aquella mujer. $Y$, caso no admitido que hubiera tratado carnalmente con ella, habría sido "con mucho gusto y voluntad de la susodicha, porque era mujer común mundana y que de ordinario vivía mal de su cuerpo y... hacia otras cosas semejantes con otros mozos y personas que querian, y de todo de mucha voluntad". Insinuó incluso que Manuela y sus amigos pudieran haber fingido los hechos para obtener beneficio. Prueba de ello es que, habiendo recibido los 30 reales, "y llevándolos la susodicha en la faltriquera, iba cantando y diciendo: los moçitos del Estrella buena me han parado mi faltriquera, y otras cosas en que declaraba el gusto que la habian dado en darla el dinero y la poca pesadumbre que llevaba de lo demás pasado" ${ }^{13}$. Viéndose acusado por varios testigos que certificaron su participación en los hechos, Jarillo daba así un giro a su defensa y pasaba a fundamentarla en la minimización del delito, habiéndose realizado, en el caso no probado de que fuese cierto, sobre la persona de una prostituta. Días más tarde volvió a tacharla de «mujer muy liviana y que vivía mal de su cuerpo y con mucha facilidad todas las personas que se querian aprovechar de ella lo hacian, no sólo en el dicho lugar del Estrella, pero en otras partes y lugares comarcanos, lo cual la susodicha hacía con mucha facilidad y gusto, y así es cosa pública y notoria en el dicho lugar y lugares comarcanos". Los testigos de su probanza tomaron esta vía y trataron de reforzar estos argumentos: el hospital estaba abandonado y en él sólo se refugiaba la gente perdida ${ }^{14}$, y Manuela Morena era una mujer fácil y liviana, "que con facilidad daba su cuerpo a quien se lo pedía". Según ratificó otro declarante, se trataba de una "mujer viandante de mala vida, y en su traza se echaba de ver, la cual estaba preñada cuando estuvo en este lugar, y decian no tenía marido"s.

Idéntica táctica adoptó a última hora el alcalde Pedro Martín Jarillo aplicándola al segundo de los casos juzgados. En el tiempo que ocupara su cargo, "siempre hizo su oficio con toda rectitud, cuidado y diligencia,

13 Y en otra declaración: “iba tan contenta por el camino que iba cantando y diciendo: de los bobos del Estrella buen atraco hago la faltriquera, dando a entender el gusto que habia recibido con el dinero que la habian dado, y que no habia recibido pena en la fuerza que la habian hecho". $Y$ repite la idea de que ella y sus cómplices lo habían planeado para sacar dinero a los mozos.

14 Testimonio de Juan Sánchez de Mateo. Según su declaración, en otros tiempos salía del hospital la procesión de la Vera Cruz el día de Jueves Santo, pero esto hacía mucho que habia cesado. En su probanza alegaba Jarillo que ces una casa vieja y caida adonde se suelen y acostumbra a recoger puercos, vacas, ovejas y otros ganados de toda suerte, sin que en el dicho hospital haya aposento alguno ni hospitalero ni hospitalera, ni en él se ha dicho ni dice misa ni otro oficio divino". En el hospital sólo se recoge "gente perdida, que, a no serlo, en el lugar se les da posada en algunas casas honradas".

15 Testimonio de Gabriel Rodríguez. Jarillo aportó, en total, las declaraciones de seis testigos favorables. 
poniéndola muy grande en averiguar los delitos... sin tener atención que tocase a sus parientes". Pero en lo que atañía al caso presente, demás de no haber podido hacer más, tenía para sí que no hubo agresores y que "por sus fines particulares la dicha mujer y el que decian ser su hermano publicaron haberla sacado de la dicha casa".

El fiscal trató de desmontar las defensas de los acusados presentando hasta veinticuatro testigos, incluyendo a Juan Pizarral y Alonso Fernández del Mazo, definitivamente enfrentados a Jarillo. El 28 de febrero concluyó sus acusaciones solicitando que se diese tormento a los acusados. Los curadores de la defensa, por su lado, elevaron a definitivas sus probanzas. Jarillo pidió la absolución por falta de pruebas, tildó a los testigos del fiscal de "vacios y no concordes" y acusó a Pizarral y Fernández del Mazo de cómplices y falsarios. El 30 de marzo, con sólo cinco encausados en poder de la justicia (Jarillo, el alcalde, Fernández del Mazo, Pizarral y Delgado) y trece en ausencia y rebeldía, el caso fue declarado visto para sentencia.

El proceso de La Estrella, si no evidencias, pues nunca podremos llegar a saber la completa verdad de lo sucedido, ofrece al historiador múltiples sugerencias para tratar de comprender algunos de los comportamientos que se daban en las comunidades rurales del Antiguo Régimen. Los dos casos de violación, sucedidos en el escaso margen de poco más de un año, presentan notables similitudes: ambos ocurrieron de noche, comportaron la saca de una mujer que dormía en un reducto cerrado y se perpetraron colectivamente. Las dos víctimas eran forasteras, una de ellas al parecer extranjera, y los agresores, participaran en uno solo o en los dos casos, fueron los mozos del lugar o, mejor dicho, los mancebos o solteros. En ambas ocasiones, en fin, sucedieron en la víspera de un día de fiesta, la Candelaria en la primera y una fiesta indeterminada del verano en la segunda ${ }^{16}$.

El ambiente festivo era extraordinariamente propicio a los excesos cometidos por los mozos, que encontraban en él una válvula de escape a una vida dura y miserable como labradores o simples jornaleros. En la víspera de la Candelaria se bebió en la taberna y se celebraron bailes, donde estuvieron algunos de los personajes que después cometerían el delito. Acabada la honesta diversión «pasadas las diez», los mozos solteros se reunieron, según parece, para continuarla por su cuenta. No era la primera vez. El propio Jarillo reconoció que "los moços del lugar las noches víspera de fiesta es costumbre salir a holgarse". Y el escribano Sebastián de

16 El dato procede de la declaración del alguacil Juan Gómez el Mozo. 
Aguilar aseguró que con este joven solían juntarse «todos los moços del lugar de noche" y ya habían llevado a cabo otras bellaquerías semejantes. Cuando se interrogaba a sus padres y convecinos, éstos mostraban su repulsa hacia tales comportamientos, pero a la hora de la verdad tendían a minimizarlos y justificarlos, protegiendo comprensivamente a sus jóvenes frente al rigor procedente de fuera de la comunidad por medio de silencios y ambigüedades. Sin la complicidad de sus paisanos, los mozos no habrian podido ocultarse o escapar a tiempo de las diligencias de los alguaciles. Fue una mujer respetada en el lugar, casada con un regidor de la villa de Talavera, quien medió a fin de solucionar satisfactoriamente para todos la travesura. Y la justicia local, obviamente emparentada con algunos de los jóvenes, hizo todo lo que pudo para que los incidentes se resolviesen sin alcanzar resonancia, circunstancia ésta que fue la que más irritó a las autoridades talaveranas.

El ritual de las violaciones se llevó a cabo colectivamente, por mucho que los testigos y algún encausado concentrasen la responsabilidad en Tomás Jarillo, si acaso el líder juvenil, y dos o tres de sus más allegados compinches. Como ya se vio, Jarillo y sus testigos de descargo describieron a Manuela Morena como una mujer de mala vida que entregaba su cuerpo por dinero no sólo en el pueblo sino en los lugares comarcanos. En cualquier caso, sorprende la presencia de estas mujeres forasteras en el momento y el sitio adecuados. Jacques Rossiaud ha constatado la existencia de "vagabundas que con o sin sus rufianes iban de pueblo en pueblo... adaptando sus rutas al calendario de ferias y mercados, peregrinaciones y principales faenas agrícolas" ${ }^{17}$. Tal solía ser el procedimiento de la prostitución rural allí donde no se disponía de una mancebía, una casa de citas encubierta o algunas mujeres que actuaban por su cuenta ${ }^{18}$. ¿Pudieron haber sido Manuela Morena y la mujer flamenca dos de esas prostitutas itinerantes? Jarillo y sus testigos, asi como algunos vecinos, así lo manifestaron o insinuaron interesadamente. En caso de darles algún crédito, cabría pensar que por alguna razón se habría roto el trato entre

\footnotetext{
Rossiaud, Jacques, La prostitución en el Medievo, Barcelona, Ariel, 1986, pág. 12.

18 Los dos últimos casos eran muy usuales en las áreas rurales, como se comprueba en el fondo de Visitas del Archivo Diocesano de Toledo. Dos ejemplos ambientados en Torrijos en el año de 1600: Un testigo "ha oído decir muchas veces en el campo que aunque deste lugar era ido el padre de las mujeres públicas, a quien por mal nombre llamaban Barrabás, pero que no hacía falta, porque en el camino de Hurtada se había vuelto la putería, lo cual se decía por la dicha Luisa Hernández y su casa, por recogerse en ella mujeres perdidas y hacerse en ellas cosas deshonestas». Respecto a las mujeres solas, valga el ejemplo de Ana Gómez, a la que un declarante acusó de umujer de mal vivir y de malos tratos, y admite a cuantos hombres quieren entrar (en su casa) para tener exceso carnal con ella", de modo que durante la noche solían entrar y salir muchos. Archivo Diocesano de Toledo, Visitas, año 1600.
} 
las mujeres y los mozos, y éstos quisieron saldar cuentas a las bravas, tomando por la fuerza aquello que creían tener derecho a obtener. Si así fuese, jamás habriamos tenido noticia de ello, como de tantas situaciones semejantes, de haberse efectuado el comercio carnal con la esperada normalidad.

Naturalmente se trata tan sólo de una hipótesis, cuya aceptación hubiera llenado de satisfacción a Jarillo, sus cómplices, y a más de un aldeano. $Y$ aunque así fuera, todavía queda preguntarse por la otra parte. Rossiaud ha hecho notar que la visita a la mancebia, y a las prostitutas rurales en este caso, podía formar parte de los ritos practicados por los grupos de adolescentes, organizados o no en "abadías". Era asimismo una prueba de normalidad social y psicológica ${ }^{19}$. Conocidos son los estudios de $\mathrm{Na}$ talie Zemon Davis y otros historiadores sobre las "abadías" de juventud en Francia ${ }^{20}$, llamadas también "bachillerías", "reinados" o "sociedades alegres". Consistían en organizaciones, más o menos institucionalizadas, de hombres solteros que habían alcanzado la pubertad. En ellas se entraba a los quince años y no se las abandonaba hasta contraer matrimonio. Debían su existencia, bien aceptada en las localidades rurales, no a una norma escrita, sino a la costumbre derivada de una experiencia secular transmitida oralmente ${ }^{21}$. Dicha costumbre otorgaba a las organizaciones de jóvenes solteros la «jurisdicción sobre los lugareños de su misma edad, incluyendo las muchachas casaderas... y sobre los forasteros que venían a cortejar a sus chicas" ${ }^{22}$. Asimismo eran garantes del correcto comportamiento de las personas casadas, controlando y castigando por medio de la burla, manifestada especialmente en carnavales y charivaris, a los casados que no engendraban hijos, los maridos engañados o dominados, los adúlteros y los viudos que contraían segundas nupcias. La violencia colectiva no era extraña a las actuaciones de estas "abadías", pero en absoluto constituían una amenaza para la estabilidad social. Muy al contrario, ayudaban a umantener el orden apropiado dentro del matrimonio y a sostener la continuidad biológica del pueblo»; defendían la identidad local frente al mundo exterior, y mediante el cumplimiento de rituales colecti-

19 Rossiaud, Jacques, op. cit., pág. 56.

20 ZEMON DAvis, Natalie, "Las razones del mal gobierno" y "Cencerrada, honor y comunidad en Lyon y Ginebra en el siglo xvil", trabajos ambos incluidos en Sociedad y Cultura en la Francia moderna, Barcelona, Crítica, 1993, págs. 83-132. Véanse asimismo las obras de MUCHEMBLED, Robert, Culture populaire et culture des élites dans la France moderne ( $x v^{e}$-xvif siècles), París, Flammarion, 1991, pág. 68 y ss.; y de BERCE, Yves-Marie, Fête et revolte. Des mentalités populaires du $\times v^{e}$ au $x v i 1^{e}$ siècle, Paris, Hachette, 1994, pág. 13 y ss.

21 BeRCE, Yves-Marie, op cit., pág. 53.

22 ZemON Davis, Natalie, op. cit., pág. 92. 
vos se integraban en el mundo de los adultos, a la vez canalizando sus instintos sexuales y preparándose para asumir el cambio que les impondría el rito de paso que supondría el matrimonio ${ }^{23}$.

Yves-Marie Bercé generaliza la existencia de tales organizaciones a toda la Europa occidental, si bien con muy diferentes grados de institucionalización ${ }^{24}$. Natalie Davis, por su parte, es de la opinión de que cel grupo juvenil de tipo tradicional duró mucho tiempo en el campo" y se prolongó más allá del siglo XVI, cuando las abadías urbanas habian dejado ya de ser grupos de edad o empezaban a encontrar contestación en las altas instancias políticas y religiosas. Las abadías están bien documentadas en Suiza, Alemania, Italia, Hungría, Rumanía, y tal vez existieron en Inglaterra, Escocia y España ${ }^{25}$. Sin embargo, los grupos de edad y las abadías de juventud han sido muy poco estudiados por la historiografía hispánica, de modo que es muy aventurado relacionar estas organizaciones con la banda de mozos solteros capitaneada por Tomás Jarillo. A lo largo del proceso no se hace mención a organización alguna, ni se da a Jarillo cualquier tipo de cargo simbólico, ni siquiera se dice que los jóvenes desempeñen alguna iniciativa en la celebración de ritos y fiestas. A pesar de todo, son llamativos algunos detalles que al menos conviene considerar.

En primer lugar, no parece que la reunión de los mozos fuera espontánea sino que respondía a una costumbre arraigada en el lugar, sobre todo en las noches previas a los días de fiesta. En el caso del hospital se trataba de la Candelaria, que, junto a las inmediatas San Blas y Santa Águeda y la precedente de San Sebastián, constituía el pórtico festivo del ciclo carnavalesco. Por otro lado, el comportamiento de Jarillo y sus cómplices responde a cierta ética conservadora, acorde con la jurisdicción que sobre la moral pública se otorgaba a las organizaciones de jóvenes. La suplantación de la justicia efectuada por el cabecilla parece en principio ir encaminada a castigar un supuesto amancebamiento, para lo cual exige a Francisco Pérez el certificado de matrimonio. El delito de violación, además, se comete sobre una mujer soltera, carente de lazos protectores, sin familia, ajena al lugar y supuestamente de mala vida. En cambio, y a pesar de las amenazas, se respeta a la mujer casada. Por último, no debe pasarse por alto el hecho de que Jarillo, erigiéndose en representante y vengador de la comunidad amenazada, diera una paliza a un albañil forastero

23 Ibidem, pág. 96 y ss.

${ }^{4}$ BerCE, Yves-Marie, op. cit., pág. 17.

25 ZeMON DAvis, Natalie, op. cit., págs. 96-97. La autora basa su hipótesis sobre España en la existencia en ella de charivaris o cencerradas y en los estudios antropológicos de PERISTIANY y PITT-Rivers. 
que había cometido el imperdonable delito de «hablar con una mujer casada" del lugar.

Pese a la completa ausencia de institucionalización, pues, los comportamientos colectivos de los solteros de La Estrella no se antojan anárquicos y espontáneos. Es posible que, como otras veces que no trascendieron, los mozos acudieran al hospital y al corral donde sabian que estaban las mujeres forasteras, fueran honestas o no, para satisfacer sus impulsos sexuales, divertirse y hacer alarde colectivamente de su hombria. Aún asi, si prescindimos de todo elemento simbólico y reducimos el caso a un mero estallido de violencia criminal, el proceso de La Estrella no pierde un ápice de su interés. Junto a los malos tratos dentro del matrimonio y las pesadumbres derivadas de la honra, la violación fue una de las modalidades de violencia sexual más extendidas en el Antiguo Régimen ${ }^{26}$. Sin embargo, los estudios realizados en España apenas recogen casos de violaciones colectivas. Como han observado ya algunos autores, ni en Valencia ni en Castilla, al menos en el siglo xv, se han hallado "casos de violaciones efectuadas por varios individuos o por bandas de malhechores", siendo así que "la mayor parte de los violadores parece que cometieron el delito aisladamente, en sólo una ocasión, y que la figura del violador "profesional" no fue habitual» ${ }^{27}$. Los que mayores semejanzas presentan con los aquí estudiados son los que Jacques Rossiaud ha registrado en la Francia bajomedieval. En la mayoría de las ciudades francesas, por aquel entonces, «la moral, tan masculina, impulsaba a los jóvenes, cuando no habían nacido en familias patricias, a constituirse en bandas agresivas perturbadoras del orden". La agresividad de estos grupos, que recorrían las calles por la noche, se traducia en violencia sexual, es decir, en violaciones colectivas. El $80 \%$ de los delitos de violación cometidos en Dijon entre 1436 y 1486 lo fueron por grupos

26 Córdoba de la Llave, Ricardo, "Violencia sexual en la Andalucía del siglo XV», en LóPEZ Beltran, Maria Teresa, (ed.), Las mujeres en Andalucia. Actas del Segundo Encuentro Disciplinar de Estudios de la Mujer en Andalucia, Málaga, Diputación Provincial, 1993, t. Il, págs. 105-126. Véase también, del mismo autor, "Violencia y adulterio en la Andalucía bajomedieval», Actas del III Coloquio de Historia Medieval Andaluza, Jaén, Diputación Provincial, 1984, págs. 263-273.

27 CÓBDOBA DE LA LLAVE, Ricardo, El instinto diabólico: agresiones sexuales en la Castilla medieval, Universidad de Córdoba, 1994. Asimismo «las fuentes valencianas no recogen un solo caso de violación colectiva, aunque sí fue habitual el rapto colectivo de mujeres". PÉREZ GaRCIA, Pablo, La Comparsa de los Malhechores, Valencia 1479-1518, Diputació de València, 1990, págs. 116-117. Claro que aún queda la reserva, debido al escaso número de investigaciones realizadas hasta el momento. No he podido consultar la comunicación de Ignacio ALMAZAN, que lleva por sugerente título el de "Grupos juveniles y violencia sexual en Terrassa durante el siglo XVi", presentada en el l Colloqui d'história de la dona. De la casa a la fabrica, Universidad de Barcelona, 22-24 octubre 1986, Papers de Treball del Centre d'Investigació Histórica de la Dona. En la publicación se incluyeron, al parecer, solamente las ponencias y no las comunicaciones. 
de jóvenes que por la noche forzaban la puerta de una mujer ${ }^{28}$. Los agresores no eran rufianes, sino hijos de las familias de la ciudad, especialmente criados, artesanos y peones; su edad oscilaba entre los dieciocho y los veinticuatro años, y su agresividad no estaba ligada a fiestas determinadas, sino que era constante a lo largo del año. Rossiaud plantea una doble motivación a esta violencia juvenil: la sanción socializada de la masculinidad en lo que funcionaba como una especie de rito de paso y la expresión de pulsaciones o frustraciones más profundas. Las víctimas eran mujeres jóvenes, preferiblemente - aunque no siempre-solteras, y en todo caso las más aisladas o débiles, o bien las pertenecientes a las capas más indefensas de la comunidad, como sirvientas o hijas o esposas de peones y trabajadores textiles.

¿Hubo en la Península Ibérica una presencia significativa de esta violencia sexual practicada por los grupos juveniles? $Y$, en tal caso, ¿subsistió hasta el primer tercio del siglo XVII? Podría pensarse que, mientras la oficialización de las mancebias ayudó a controlar en las ciudades las pulsiones sexuales de un modo ordenado y pacífico, en las áreas más marcadamente ruralizadas, donde estas casas no existian, pudieron perdurar más tiempo estas formas de violencia procedentes de tiempos medievales. Cabría, sin embargo, otra hipótesis, pues precisamente en 1623, tan sólo dos años antes del primero de los sucesos de La Estrella, Felipe IV acababa de prohibir las mancebias públicas de modo que, en casos extremos, hubo de recurrirse a antiguos procedimientos violentos de satisfacer la líbido ${ }^{29}$. Sorprende la semejanza de los episodios estudiados con los de la Francia bajomedieval. En La Estrella las víctimas fueron también mujeres solas o escasamente protegidas y, lo más importante, ajenas a la comunidad local, siendo las mujeres propias, según se desprende, intocables. En cambio, la banda de agresores estaba formada por hijos de vecinos, labradores y jornaleros, con edades comprendidas entre los veintidós y treinta y dos años en el momento de los hechos. La edad de algunos mancebos parece, en algunos casos, bastante elevada ${ }^{30}$, lo que denota dificultades para contra-

28 Rossiaud, Jacques, “Prostitution, Jeunesse et Socièté dans les villes du Sud-Est au Xve siècle», Annales. Économies, sociétés. Civilisations, $31 \mathrm{e}$ année, n. ${ }^{\circ} 2$ (mars-avril 1976), págs. 289-325; y la obra ya citada La prostitución en el Medievo, sobre todo el capítulo ll de la Primera Parte titulado "Orden sexual, subversiones juveniles e instituciones mediadoras", págs. 23-41. Para lo que sigue, me remito a las páginas indicadas de esta obra.

29 “Ordenamos, y mandamos que de aquí adelante en ninguna Ciudad, Villa, ni Lugar de estos Reinos, se pueda permitir, ni permita mancebía, ni casa pública, donde mujeres ganen con sus cuerpos", Tomo Segundo de las Leyes de Recopilación, que contiene los libros Sexto. Séptimo y Nono, Madrid, Imprenta Real de la Gazeta, 1772, Libro octavo, Título 19, Ley VIll, pág. 425.

30 Tanto Juan Fernández como Alonso Fernández del Mazo tenian unos treinta y dos años en 1625. Ambos figuran como labradores, mientras que los más jóvenes aún son simples "trabajadores". 
er matrimonio, ya fuesen derivadas de carencias económicas o desequilibrios demográficos. Tales problemas solían enfrentar a los solteros con los casados, pero sobre todo con los forasteros o viudos y segundos contrayentes que amenazaban con disputarles la reserva local de mujeres casaderas. Aunque la hostilidad y reticencias hacia lo que venía de afuera es patente a lo largo del proceso, no hay datos de que los mozos organizasen cencerradas, aunque ya se vio la reacción de Jarillo frente a un forastero que pretendía a una mujer casada. La respuesta frente a los forasteros intrusos podía ser la violencia; en cuanto a las forasteras, parecian considerarlas un patrimonio común.

En la España medieval fueros y partidas condenaban a muerte el delito de violación, pero esta pena casi nunca se aplicó, siendo usuales las de multa y destierro ${ }^{31}$. Existía una casuística, además, que en nada favorecía a las víctimas. En primer lugar, los canonistas venían insistiendo desde hacía siglos en que "la gravedad de una violación dependía en gran medida de la resistencia ejercida por la mujer", que debía gritar y defenderse para obligar al forzador a emplear la violencia, factor que otorgaba al suceso un carácter delictivo ${ }^{32}$. Las dos víctimas de La Estrella así lo declararon, acompañándolo de lloros y exhibición de heridas. Ambas activaron la denuncia de inmediato, otro de los requisitos para que se les otorgase credibilidad. Finalmente, la gravedad del delito dependía de la condición de la víctima. No era igual que la violada fuese una burguesa respetable o una sirvienta, y mucho menos una prostituta. En este último caso, se tendía a atenuar la pena ${ }^{33} y$, si bien esta circunstancia no quitaba al acto la consideración de delito, la víctima veía muy disminuidos su credibilidad y los recursos legales a su favor, al igual que la comprensión de la justicia ${ }^{34}$.

\footnotetext{
31 Cordoba de la Llave, Ricardo, El instinto diabólico..., págs. 71-76.

32 Ibidem, pág. 54.

33 La Hermandad renovada por Enrique IV en 1473 llegó a considerar caso de hermandad "Solamente la fuerza de mujeres doncellas, casadas y viudas que no fuesen "mondarias" públicas, a saber, prostitutas", BARros, Carlos, Mentalidad justiciera de los irmandiños, siglo XV, Madrid, Siglo XXI, 1990, pág. 218.

34 El vocablo "violación" es un neologismo. CovarRubias, Sebastián de, en su diccionario citado, utiliza el de "forçar", que "a veces significa conocer una mujer contra su voluntad", op. cit., pág. 411. Sorprende la parquedad de la legislación sobre los delitos de violación en la España moderna, y cuando la Nueva Recopilación hace una mención, la disposición legal se remonta a tiempos medievales. Por ejemplo, la Ley IV, Título 23, Libro octavo: “Todo hombre, que matare a otro a sabiendas, que muera por ello; salvo si matare a su enemigo conoscido, o defendiéndose, o si lo hallare yaciendo con su mujer, do quier que lo halle, o si lo hallare en su casa yaciendo con su hija, o con su hermana, o si le hallare llevando mujer forzada para yacer con ella, o que haya yacido con ella...", Tomo Segundo de las Leyes de Recopilación..., pág. 433. Tampoco parece que, en general, los eclesiásticos diesen al tema excesiva amplitud en los libros de confesores. Benito Remigio Noydens, por ejemplo, ligó la violación al pecado de “rapto», para el que se
} 
De ahí los intentos de Jarillo para probar la deshonestidad de Manuela Morena para el caso de que se consiguiese probar fehacientemente el delito que aún se obstinaba en negar.

Las sentencias del proceso de La Estrella fueron leídas finalmente el 11 de abril de 1628. Tomás Martín Jarillo, que llevaba más de siete meses en la cárcel, fue condenado «a rigurosa cuestión de tormento cuya calidad y cantidad y le reiterar en él una y más veces reservo en mí". Sobre su pariente Pedro Martín Jarillo, por su negligencia probada, cayeron un año de suspensión del oficio de alcalde y $2.000 \mathrm{mrs}$. de multa. A Juan Delgado, Juan Pizarral y Alonso Fernández del Mazo se les imponía una multa de $1.000 \mathrm{mrs}$. a cada uno, pagando la cual serían libres. Finalmente, a los trece mozos que aún se encontraban en la situación de ausencia y rebeldía se les castigaba con cuatro años de galeras, el pago de las costas y una multa de $20.000 \mathrm{mrs}$. a cada uno.

Las sentencias tuvieron dos efectos inmediatos. El curador de Jarillo apeló a la chancillería de Valladolid y al Consejo Arzobispal, mientras que, al cabo de veinte días, empezaron a entregarse los prófugos. Cinco de ellos lo hicieron el 2 de mayo y más tarde lo harían otros tantos. Únicamente no hay constancia de que se entregasen Pedro Gómez y los hermanos Miguel y Juan Mirado. Todos realizaron sus confesiones, unos negándolo todo, otros en la línea colaboradora de Pizarral y Fernández del Mazo (Andrés Sánchez, Juan Fernández); la mayoría dijo no saber quiénes eran los culpables, pero no faltó quien volviese a cargar la responsabilidad sobre Jarillo. Habiéndoles oído, el fiscal les acusó de rebeldía y de la perpetración de delitos "atrocísimos", calificándoles de "raptores violentos y forzadores de mujeres".

El 3 de agosto de 1628 formalizó Jarillo su apelación ante el Consejo Arzobispal, alegando "las causas de nulidad y agravio que del proceso y autos de él resultan». El alcalde mayor de Talavera le había condenado a tormento sin tener pruebas ni indicios ciertos, él había sido implicado por cómplices que con ello trataban de exonerarse de su delito y, en fin, el resto de las imputaciones eran tan leves que un año de cárcel, que estaba próximo a cumplir, era un castigo más que suficiente. En el otro sentido, el fiscal Pedro González Tonel habia apelado a la chancilleria por estimar que los delitos de Jarillo merecian la pena de muerte, y en consecuencia

requiere "que haya robado la mujer contra su voluntad o la de sus padres o tutores con fin de luxuria o la de casamiento, y que sea llevada de una parte a otra, alias, no sería rapto si no cópula tenida con violencia". Promptuario moral de questiones prácticas y casos repentinos en la Theologia Moral, para examen de curas y confessores, Madrid, Por Melchor SanCHEZ, 1664, pág. 160. 
solicitó la inhibición de la justicia arzobispal. El 17 de agosto, sin embargo, el proceso fue remitido al abogado de la Dignidad, el licenciado Ruiz de Mobellán, que seis días más tarde revocó la sentencia de tormento y condenó a Jarillo a pagar las costas y $4.000 \mathrm{mrs}$. de multa y a seis años de destierro de Talavera y su jurisdicción, so pena de galeras. El procurador de Jarillo aceptó la sentencia después de conseguir que, además, se le condonasen los $4.000 \mathrm{mrs}$. por su condición de pobre. El 31 de agosto el alcaide recibía una orden para que soltase al preso en el plazo de dos horas. Y de nada sirvió, al parecer, la apelación del fiscal ante Su Santidad y su Sede Apostólica.

Fue precisamente entonces, cuando empezó a correr la noticia de la benigna sentencia, que se entregó la segunda tanda constituida por cinco mozos. Las perspectivas eran igualmente favorables para todos ellos. En efecto, el juez del Consejo, Francisco Francés Zorrilla, revocó asimismo la sentencia de galeras y les dio por libres, condenándoles solamente a pagar las costas. El fiscal también apeló esta sentencia, pero no hay noticias de que su iniciativa prosperase.

El Consejo Arzobispal mostró así su benevolencia ante unos acusados cuyas travesuras juveniles no fueron juzgadas como demasiado graves, al menos en proporción a la resonancia que estaban provocando las diligencias procesales. Sospecho que los alcaldes talaveranos compartían en buena medida esta mentalidad y que el rigor de que hicieron gala se debió menos al escándalo producido por unas violaciones sucedidas hacía tiempo y perpetradas en las personas de mujeres forasteras y sin relevancia, en paradero desconocido y quizá de vida deshonesta, que a las negligencias y ocultaciones con que la justicia delegada de La Estrella había menoscabado el principio de autoridad encarnado en la villa. Por su parte, el Consejo Arzobispal demostró a su vez que el arzobispo era el verdadero señor de la tierra. Los casos de violencia sexual ocurridos en La Estrella acabaron por convertirse en una mera excusa; y Tomás Jarillo y sus compañeros de diversión, en una cabeza de turco que, no obstante, salió beneficiada de la pugna de intereses enfrentados. 